\title{
Ambiência virtual de estudos: aves ou livro aberto em rede
}

\section{Virtual studies ambience: birds or web open book}

\begin{abstract}
Resumo: Trata-se de expor o conceito e alguns desdobramentos concretos de ambiências virtuais de estudos, aves, criadas para congregar escritos, vídeos, imagens e pensamentos sobre assuntos específicos e diversificados. O conceito se aplica ao campo das tecnologias contemporâneas envolvidas na didática das artes e giram em torno do problema da articulação pessoal-social na rede mundial de computadores. As aves apresentadas se voltam para a pesquisa teórico-prática de imagens interativas e linguagens multimidiáticas a fim de investigar novas potências de comunicação na cibercultura. $O$ artigo constitui-se como relato dessa pesquisa, como corpo teórico e arcabouço conceitual da prática de criação das ambiências virtuais de estudos. Nele conclui-se que essas aves são uma espécie de livro didático-poético aberto em rede e mostra-se a vantagem que essa ideia representa, para a arte, em relação à de livro eletrônico tradicional, os atuais e-books, fechados, vendáveis, raros, caros e pouco afeitos à interação multidimensional.
\end{abstract}

Palavras-chave: Ambiência. Virtual. Estudos. Rede. Cibercultura. Abstract: In this paper I expose the concept and some con-
crete developments of virtual ambiences for art studies, called
birds. At these ambiences, we can bring together writings,
videos, images and thoughts on specific and diverse subjects.
This concept focuses to the field of contemporary technologies
involved in teaching arts and to the link personal-social on the
world wild web. The birds presented come from a theoretical
and practical research of interactive images and multimedia
languages to investigate new powers of communication in the
cyberspace. The article is a report of this research and also,
it is theoretical and conceptual framework of the practice of
creating virtual ambiences of studies. It concludes that these
birds are a kind of poetical textbook open in the network and
shows the advantage that this idea represents, for art, in rela-
tion to traditional electronic book, the current e-books, mar-
ketable, rare, expensive and somewhat closed for the multidi-
mensional interaction.
Keywords: Ambience. Virtual. Studies. Network. Cybercultu-
re. re.

BARROSO, Ana Beatriz. Ambiência virtual de estudos: aves ou livro aberto em rede. Informática na Educação: teoria e prática, Porto Alegre, v. 16, n. 1, p. 139-148, jan./jul. 2013.

\section{Ana Beatriz Barroso \\ Universidade de Brasília}

\section{Introdução}

$\mathbf{N}$ arra-se neste texto a criação de espaços virtuais propícios ao estudo, como são alguns livros, a fim de pensar o processo lento da construção de sentidos e saberes, subjacente aos processos de transmissão, assimilação e transformação de conhecimentos - ensino e aprendizagem. O estudo, que ainda não se constitui como pesquisa propriamente dita, precisaria de um lugar de pausa sobre o movimento confuso onde se misturam a necessidade de entender o que já se encontra dado e a vontade de criar, experimentalmente, o que ainda não existe. Este lugar compor-se-ia de ambiências hipertextuais onde pudéssemos anotar pensamentos, agrupar informações, organizar conexões e criar entendimentos sobre temas específicos ou objetos de interesse. Chamadas de aves, essas ambiências virtuais de estudo derivam da ideia de ambiente virtual de aprendizagem, $\mathrm{AVA}^{1}$, construído na rede mundial de compu-

${ }^{1}$ Cf. o AVA do Arteduca, arte-educação a distância no Instituto de Artes / UnB. http://www.arteduca.unb.br/ 
tadores sobre a plataforma Moodle, cujo uso vem sendo amplamente disseminado, tanto no ensino presencial - como espaço de apoio e acompanhamento de trabalhos disciplinares quanto no ensino a distância.

As aves advêm do desejo de subjetivação de um espaço formado no domínio público, normalmente objetivado. Consequentemente, criar aves é como escrever cadernos pessoais dentro de um livro aberto, mas cadernos pessoais onde não se encontra exatamente a pessoa, nem a completude das coisas encontradas, mas sim, apenas, o traçado das buscas e algumas cristalizações. Uma ave é um caderno de estudos aberto à interação.

Isso, por outro lado, só se tornara possível tecnologicamente, num dado momento, porque só então popularizara-se uma interface extremamente amigável de criação para espaços multimídia e interativos na rede mundial de computadores, o blogger. Os blogs são páginas eletrônicas pré-fabricadas, cuja hospedagem é feita automaticamente, sem ônus, no momento em que se começa a criá-los. Pela série de recursos que disponibilizam e pela facilidade que geram, eles vêm sendo utilizados por pessoas comuns nas mais diversas situações. Em relação aos ambientes educativos criados no Moodle, os blogs têm a vantagem de poderem estar desvinculados de um espaço escolar ou cultural predeterminado. A ideia de ave, porém, comum a blogs e moodles, constitui-se principalmente em lugares de silêncio e articulação perdidos na rede.

\section{Ateliê aberto}

Anterior ao conceito de ave acima exposto, o ateliê aberto - www.abeatrizb.com - foi surgindo da vontade de deixar alguma arte à mostra na rede mundial de computadores. Não podia ser uma galeria, nem um portfólio; era mesmo um ateliê porque, como espaço virtual, era lugar de construção investigativa, mais do que de exibição. O lugar se faz de portas, quintal e asas: zonas de escrita, pintura, desenho, fotografia e exposições. Por dentro se encontra um pequeno labirinto. Como é muito pessoal, não cabe aqui descrever seus desdobramentos interiores. Dele importa apenas saber isso: nele se fez o ninho das aves.

\section{Animaemrede}

Essa ave - http://animaemrede.blogspot. com.br - já nasceu junto à ideia de ambiência virtual de estudos como caderno pessoal para reunir materiais e pensamentos sobre imagem, movimento, tempo, espaço, artes. Por estar em domínio público, foi pensado como lugar aberto a estudantes universitários, por uma questão de familiaridade. Ele se estrutura em dois ambientes desiguais: um trata da gênese do cinema e o outro, de noções de linguagem. A página inicial acolhe e introduz o assunto. Nessa página de boas vindas há duas colunas onde se distribuem textos, imagens, vídeos e conexões. Ela é uma apresentação geral e ilustrada da ambiência e propõe uma série de reflexões, como a seguinte.

Ora, ao contrário do ciclope paralisado que abre os olhos por uma fração de segundos, os seres humanos normalmente vêem o mundo, no qual se movimentam, com dois olhos. O que significa isso? No mínimo que a imagem fotográfica não é tão realista quanto supõe o senso comum ingênuo. Isso é uma crítica à fotografia, não no sentido de tomá-la como excessivamente representacional, mas, ao contrário, no sentido de considerá-la insuficientemente representacional ou, melhor 
dizendo, insuficientemente realista. Mais do que tudo, o que essencialmente falta à fotografia é o tempo. De fato, a fotografia necessariamente capta apenas um instante do fotografado. Ora, a nossa visão do mundo se dá no tempo (CÍCERO, 2008, p. 36).

A página contém ainda algumas saídas discretas, áreas de dispersão para viajantes e uma seleção de referências correlatas, como os bisões de Altamira e os cavalos de Muybridge, uma pintura rupestre da Serra da Capivara, o homem vitruviano de Leonardo da Vinci e uma mulher vitruviana (de maiô) de Melvin Sokolsky, fotógrafo norte americano. Dela se sai para dois ambientes distintos: o dos brinquedos ópticos, chamado animagênese, e o das questões sobre linguagem, o animalínguas. 0 princípio norteador do conjunto, da ambiência toda propriamente dita, é de ordem poética: não se pretende informar, nem explicitamente ensinar, mas criar condições para associações, genuinamente pessoais, entre as partes fragmentadas que compõem um mesmo tema. Não deixa de ser uma didática. As páginas secundárias têm o mesmo pano de fundo e quase a mesma estrutura da página inicial. A uniformidade do desenho gráfico visa criar, justamente, a sensação de ambiência. Também em ambas encontram-se textos, imagens, conexões e vídeos relacionados ao assunto: a construção é principalmente de investigação seletiva, coleta e organização do material.

O animagênese trata dos primórdios da imagem em movimento. Ele propõe um início de entendimento do cinema pelo universo lúdico dos brinquedos óticos, apresentando-os por meio de desenhos e vídeos. Os textos não são numerosos e aparecem tanto na coluna da esquerda quanto na coluna da direita, comentando cada objeto, desde a câmera escura até o cinematógrafo. Fala-se didaticamente da lanterna mágica, tataravó do projetor de slides ou avesso da câmera escura, já que faz a luz ir para fora da caixa preta, atravessando no caminho um vidro colorido. Fala-se do taumátropo, do fenaquistocópio e do estroboscópio. Ao apresentar-se o flipbook, sugere-se que nos cantinhos dos cadernos criemos histórias simples variando o desenho um pouco em cada página e passando depois, em um ritmo que nos permita sentir o movimento. Seria uma boa maneira de praticar animação. No mesmo tom, fala-se do praxinoscópio, espécie de zootropo. A diferença é que, além da roda maior, com as imagens seqüenciais desenhadas, há no centro uma roda menor, composta por espelhos. Vemos as imagens animadas na roda maior refletidas nesses espelhos da roda menor e o efeito fica mais agradável.

Chega-se à cronofotografia, de Étienne-Jules Marey: uma ave em vôo, um salto com vara em etapas. Recorda-se: essas imagens eram feitas com um aparelho chamado fuzil fotográfico. Parecia um revólver, mas em vez de tirar vidas, tirava fotos, permitindo registrar as sucessivas etapas de um movimento. Depois disso, o cinetógrafo ou máquina de filmar, de Thomas Edison, assim como o cinematógrafo, dos irmãos Lumière, talvez já fossem mais que brinquedos, já que inauguravam de fato uma série mais complexa de tecnologias da imagem em movimento. O ambiente se encerra, assim, com uma mostra dos primeiros filmes, de 1895, dos irmãos Lumière. Propõe-se, então, voltar ao animaemrede ou ao animalínguas, para dar a sensação de círculo, ambiência fechada, mas sugere-se igualmente ir além e desaguar em uma breve história da animação por tópicos, em um parque de produções de brinquedos cinemáticos ou no quadro a quadro dessa história, outros espaços-aves na rede. 
Já o animalínguas trata de coisas que se falam através de algumas técnicas. À esquerda há vídeos, à direita, textos. A idéia é propiciar a apreciação de brincadeiras estranhas com imagem em movimento e linguagem multimídia, assim como constituir-se em lugar de entrada para aprofundamento técnico e esclarecimento de noções fundamentais, como a de linguagem, apresentada, nesse contexto, como sendo um sistema articulado de signos que nos permite ampliar virtualmente nosso poder de comunicação, isto é, nossa capacidade de criar relações e dar sentido a existências. O texto se abre, assim, para a constatação de que não há arte sem técnica e apresenta uma lista de conexões que visam aparelhar estudantes que queiram explorar técnicas tradicionais e contemporâneas de animação. Surge, novamente, a velha encruzilhada entre animaemrede e animagênese.

\section{Aves avessas}

A natureza não é um objeto (Gegenstand) inerte, que se pode utilizar à vontade; tem uma força intrínseca que se investe, segundo as ocorrências, de fatos de cultura, e que não deixa, assim como veremos mais adiante a propósito do espaço, de fazer sociedade. De um modo particularmente evidente, esses investimentos exprimem-se na poesia. Essa, de uma maneira paroxística, é um resumo do mundo no seu todo (MAFFESOLI, 1996, p. 243).

As primeiras aves - ateliê aberto e animaemrede - originaram-se de processos distintos. $\mathrm{O}$ ateliê surgiu da vontade de expor e pensar um espaço expositivo particular na rede (pública?) mundial de computadores. Já o animaemrede foi oriundo de um trabalho em equipe, a título de conclusão de um curso de especializa- ção; o nome, inclusive, foi dado por um colega. Apesar dessa distinção, esses lugares virtuais fundaram e concretizaram, de algum modo, o conceito de ave como ambiência virtual de estudos.

No desdobramento desse conceito, começaram a aparecer aves diversas, assim autodesignadas ou não. Isso porque, a partir desse conceito, a maneira de se perceber outros lugares virtuais se transforma. Passa-se a ver uns como lugares de estudo e a construir outros também com essa mesma ideia. A navegação se modifica. Para agrupar o bando de aves que então foi se formando, tornou-se necessária uma ambiência de bastidor, uma ambiência às avessas, que se destinasse a registrar investigações e olhares. Essa ambiência - http:// avesavessas.blogspot.com.br - apenas leva a outras. Em si, constitui-se como caderneta de indicações, rascunhos, anotações, coisas de valor irrisório. A quem pode interessar o avesso das coisas, seus alinhavares, seus pontos sem nó, suas linhas descosturadas? Nesse caso, o fato de se estar em espaço aberto - a rede - é mero detalhe, que só tem relevância por evidenciar até que ponto o conceito mesmo de caderno pessoal já se percebe dependente das anotações de outras pessoas, das pesquisas partilhadas, dos vídeos despretensiosos e bons, das charges e cartuns que nos chegam quase que do anonimato por meio da dinâmica da rede, do estar em rede, solto, horizontalizado, imerso nos múltiplos delírios individuais em fluxo e suscetível à publicidade pulverizada que faz de todos nós potenciais consumidores, inclusive, de cultura.

A ambiência das avesavessas, por mais avessa que seja ao social, por mais que queira se constituir como lugar de intimidade, torna clara a relação de compartilhamento que se estabelece, quase que por si só, na rede mun- 
dial de computadores. Por mais que se queira ficar esquecido ou perdido em seu canto, andar na contramão das comunidades de aprendizagem, das redes sociais, dos fóruns e listas de discussão, a estrutura da rede nos impele ao contato, ainda que multidirecional e discretíssimo, com os outros, suas ideias, sonhos e incertezas. Desse contato sutil, quase não quisto, eclode, contudo, uma força particular, uma potência de comunicação fundadora do jogo de citações que dilui a noção de autor na de sujeito falante e prepara o sujeito da linguagem. Tornamo-nos, ou conscientizamo-nos de ser, sujeitos recitantes. Nossa novidade ou, se preferirmos, nossa subjetividade, nesse lugar-tecido, afloraria na originalidade da colagem feita ao experimentarmos essa potência comunicacional específica e recente: a escrita multimídia em rede. Seria no todo, no aspecto geral dos fragmentos ou citações, que perceberíamos a beleza do mosaico, assim como seria na articulação das partes (cacos de vídeo, pedaços de fotos, trechos de textos etc) que se diria algo de fato próprio, original ou subjetivo na rede - espaço obsubjetivado, lugar comum, cotidiano nosso na cibercultura.

No brilhante conto em que imagina seu próprio encontro com um outro homem no futuro, Borges cogita sobre a língua como um sistema de citações. A certa altura do diálogo, os personagens trocam as seguintes palavras:

Completados os cem anos, o indivíduo pode prescindir do amor e da amizade. Os males e a morte involuntária não o ameaçam. Exerce alguma das artes, a filosofia, a matemática ou joga um xadrez solitário. Quando quer, se mata. Dono de sua vida, o homem também o é de sua morte.

Trata-se de uma citação? - perguntei.

Certamente. Já não nos restam senão citações. A língua é um sistema de citações (BORGES, 2009, p. 79).
Na articulação, solitária embora em rede, dessas citações é que nos encontraríamos ou nos inventaríamos, já que é nesse espaço-tempo da comunicação em rede que nos encontramos e desencontramos, é aqui que nos tocamos e esbarramos com o outro e com suas outras culturas. Sempre haveria, evidentemente, algo novo a dizer na medida em que cada ser é novo e único e experimenta à sua maneira o conjunto de sensações que the chega pelos cinco sentidos e com ele interage através de ações e de representações. A eterna novidade seria, assim, o ter sempre algo novo a dizer ou a ilusão de tê-lo. A língua como sistema de citações não aniquila a possibilidade de emergência da palavra original, apenas torna clara a premência do sistema sobre o indivíduo particular. O sujeito, ou uma vaga ideia de sujeito (que seja), diferiria da vaga ideia de indivíduo particular no momento em que a pessoa se visse na linguagem (BENJAMIN, 2000), como agente de adaptação e transformação criativa no sistema sígnico. A pessoa na linguagem apresenta-se, ela também, como uma questão já respondida de diferentes maneiras, mas ainda aberta, como uma ferida incurável, transbordante de pulsões vitais: como uma imagem viva da incompletude.

\section{Disciplinas}

O processo de invenção, construção, usufruto e conceituação de ambiências virtuais de estudo até aqui descrito desenrolou-se junto a um outro processo semelhante, de exploração de um tipo de ambiente virtual, assim como o blog, também já pré-fabricado, mas concebido claramente para auxiliar e viabilizar o ensino à distância. Trata-se da plataforma Moodle, mencionada mais acima. Apesar desse tipo de ambiente não proporcionar a mesma liberdade 
de uso e acesso proporcionada pelos blogs, ele apresenta características semelhantes. Uma delas é o desenrolar vertical. Há uma divisão por semanas e uma série de recursos interativos correlacionados, como fóruns, espaço para envio de tarefas, acesso a textos e galerias, páginas eletrônicas etc., como se fosse uma mini rede. Nessa mini rede, constrói-se um micro universo expansível sobre o tema da disciplina, organizado em semanas, módulos ou como o autor considerar melhor. Alunos, tutores e professores interagem nesse universo, que, embora comum em princípio, é explorado distintamente por cada pessoa. Novamente, abre-se espaço para um tipo singular de subjetivação a partir de um lugar partilhado, objetivado em muitos aspectos, mas não em todos.

Essa tecnologia e outras criadas com o mesmo fim - viabilizar processos de ensino-aprendizagem à distância por meio de AVAs (ambientes virtuais de aprendizagem) - podiam, portanto, perfeitamente, serem usadas para criar ambiências virtuais de estudos, aves. A tecnologia do Moodle seria, nessa nuance, concebida como ferramenta de criação para lugares de estudo mais exigentes, tanto do ponto de vista do desenvolvimento teórico quanto do desenvolvimento de habilidades técnicas. Nisso consistira seu caráter disciplinar. Haveria ali um conjunto organizado de informações, sugestões, elucubrações e possibilidades a serem exploradas de modo sistemático pelo estudante interessado em adquirir competências específicas.

Diferentemente das aves-blog, maleáveis e flexíveis, as aves-avas nos levariam a experimentar o rigor e a precisão na conquista de metas pré-definidas. As disciplinas eram assim, na rede, espécies de laboratórios onde reflexão e prática mesclavam-se por meio de elementos concretos: exercícios, textos, refe- rências audiovisuais, infográficos, conexões. Nelas, as avaliações eram vistas como registro de aferição ou conjunto de informações importantes nas tomadas de decisão, base para os rearranjos que toda dinâmica exige. As aves-avas ganhavam aos poucos o aspecto de livro-base, apostila, caderno aberto, comum, lugar partilhado entre estudantes, fio condutor da construção da matéria tratada na disciplina. Esse caráter fazia com que o espaço virtual se tornasse efetivamente real, frequentado, e portanto gerador da sensação de haver uma concretude, uma argamassa translúcida, talvez, uma liga entre as pessoas envolvidas no entendimento elaborado de um assunto. Não um assunto definido de modo autônomo, como no animaemrede, por exemplo, mas um assunto contextualizado no fluxo curricular de um curso (de graduação ou pós-graduação, de nível técnico ou similar), pensado coletiva e institucionalmente. Tudo isso altera muitos parâmetros.

Os ambientes disciplinares, assim concebidos, são extensões das aulas, são a "realidade ampliada" da escola ou da universidade e, mais de perto, dos cursos. No Moodle, as disciplinas assumem duas configurações ligeiramente distintas. Em uma, o ambiente virtual de aprendizagem complementa o espaço físico da sala de aula e consolida-se como suporte de alto valor, com orientações, quadro de acompanhamento e materiais digitalizados. Configura-se, assim, como mais um espaço de interação e relacionamento entre todos, alunos e professores. Em outra configuração, o uso do AVA é mais integral e menos complementar. Aqui enquadram-se os cursos semipresenciais ou quase totalmente a distância, que acontecem via rede, num ambiente cuidadosamente preparado para o desenrolar das atividades que compõem a agenda da disciplina e que explo- 
ram várias das ferramentas de interação interpessoal e computacional disponíveis na plataforma - o que não é tão necessário nos cursos presenciais. Ainda que cada pessoa desenvolva sua maneira de organizar e dispor temas, problemas e dinâmicas educativas individuais ou em grupo, os AVAs impõem uma sistemática relacional particular, claramente voltada para processos de ensino-aprendizagem, os quais podem ser vivenciados como processos de estudo dirigido, direcionado e observado de perto por outrem - alunos, tutores e professores. Nisso, sim, são radicalmente diferentes dos blogs, que podem ser usados de múltiplas formas para os mais variados fins.

As aves-avas, finalmente, podem ser traduzidas por ambiências virtuais de estudos disciplinares e servem como poderosas aglutinadoras de artigos, informações, imagens, referências e práticas experimentais. Elas são apostilas eletrônicas, diários de classe, livros ou cadernos didáticos virtuais. São, sobretudo, a junção de tudo isso em um só lugar, precário e incompleto, inegavelmente, porém apropriado para gerar um leque de escolhas possíveis de aprofundamento em um ou outro aspecto do campo do conhecimento em que se pretende aventurar.

\section{Considerações finais}

As quatro experiências aqui descritas levam-nos a concluir que, talvez, o que estejamos chamando de aves, ambiências virtuais de estudos e suas variações, nada mais sejam que um conceito germinal de livro aberto em rede, se pensarmos o livro como lugar de estudo e poética. Essa ideia de livro aberto em rede soa mais atraente que a de livro eletrônico (fechado e comercializável), porque mais leve, concreta, atual e acessível. Nesse caso, a própria rede já é vista como um grande livro, dentro do qual qualquer um escreve seus capítulos, páginas e índices. O livro-rede, inclusive, já possui um tipo especial de leitor.

Trata-se, na verdade, de um leitor implodido cuja subjetividade se mescla na hiper subjetividade de infinitos textos num grande caleidoscópico tridimensional onde cada novo nó e nexo pode conter uma outra grande rede numa outra dimensão. Enfim, o que se tem aí é um universo novo que parece realizar o sonho ou alucinação borgiana da biblioteca de Babel, uma biblioteca virtual, mas que funciona como promessa eterna de se tornar real a cada "clique" do mouse (SANTAELLA, 2004, p. 170).

Essa imensa biblioteca, contudo, é repleta de áreas restritas e livros com volumes e capítulos fechados. Mesmo a ideia de livro, embora sedutora, não se adequa exatamente à rede, é mais uma metáfora. Não se adequa porque, em sentido estrito (HOHLFELDT; MARTINO, 2001), o que faz um meio ser definido como meio de comunicação é sua dupla capacidade de transmitir mensagens com certo grau de clareza ou precisão e de garantir-lhes certa robustez, de modo que elas possam perdurar no tempo (atravessar gerações) e no espaço (dialogar com outras culturas). É isso que faz a diferença, por exemplo, entre a Pedra de Roseta e um conjunto de silvos sincopados informando que o inimigo está próximo. Em outras palavras, o que se diz aqui é que talvez a rede mundial de computadores ainda não seja exatamente um meio de comunicação. Experimentamos nela, indubitavelmente, novas dimensões comunicacionais - hipertextualidade, desconexão tempo-espaço, aproximação virtual de espaços distantes, prolongamentos sensoriais etc. - no entanto, não temos garantia alguma de que 
isso vá perdurar, ou melhor, de que aquilo de mais significativo que possamos produzir nessas condições multidimensionais vá ficar, permanecer, sedimentar-se ou infiltrar-se no solo/ fluxo cibercultural.

Não se trata de ambicionar um futuro ou a eternidade, mas de encontrar um modo de fazer a linguagem multimídia, hipertextual e interativa se realizar plenamente no presente em um meio fixador de comunicação. É como se a escrita, traço de nossa entrada na História, estivesse se tornando, na cibercultura, tão fluida, efêmera, cotidiana e pragmática quanto a fala. Sem desenvolver demoradamente esses aspectos, que acabam sendo o pano de fundo desta pesquisa, pode-se pensar que, se o salto da fala para a escrita nos lançou na História, o salto da escrita para algo ainda mais complexo pode nos lançar efetivamente nisso que vem sendo chamado de pós-história, caracterizada como uma dissolução do sentido unitário de História pela percepção (tornada possível com as atuais tecnologias de comunicação) das múltiplas histórias, não hierarquizáveis, mas enoveladas e aparentemente caóticas, que compõem a realidade.

O referido salto não é a rede mundial de computadores quando se admite que a rede, em seu estado tecnológico atual, é mais canal que meio - na acepção estrita do termo - porque ainda não nos permite registrar, gravar ou fixar em profundidade (isto é, preservando-se as várias dimensões e camadas de sentido experimentadas na comunicação hipertextual) as mensagens que ali circulam em linguagem multimídia interativa. É como se estivéssemos diante da câmera escura ainda desprovida da parte fotoquímica (e, hoje, digital) que permite fixar a imagem pequena e invertida da luz física que entra. É o salto à fixação que transforma a câmera escura em câmera fotográfica e que nos permite ver a fotografia como meio de comunicação, apesar do caráter polissêmico (e, portanto, impreciso) de suas imagens que, diga-se de passagem, passam por um intenso processo de codificação desde o advento da indústria cultural e sua expansão pautada na reprodutibilidade técnica das imagens. De modo semelhante, não seria o livro virtual o meio de comunicação capaz de resolver o problema da permanência a longo prazo do conhecimento gerado no multiculturalismo da rede? Isso parece ser possível quanto mais esse livro for oriundo e apartado da rede mundial de computadores. O que acontece hoje é que o livro eletrônico (que não equivale ao livro aberto em rede, nem à ave) nasce como se nascesse para o papel, ele é monomídia em sua origem.

Sabe-se que um meio de comunicação e a linguagem que ele engendra não nascem prontos, mas se formam aos poucos a partir de referências anteriores, que norteiam a experiência no novo meio, e das práticas sociais que condicionam sua existência em dada época. A experiência ganha consistência na medida em que se investigam as características e potencialidades específicas desse novo meio. É isso, por um lado, o que a criação das aves nos mostra e o que nos propomos a valorizar ao explorar as dimensões cada vez mais híbridas das linguagens da arte na rede e em rede, onde o leitor monta um percurso não-linear de leitura, cambiante como seu universo de interesses. A combinação de traços multimídia, interação, sociabilidade e hipertextualidade, típicas da comunicação na rede mundial de computadores, representam o diferencial desta ideia, originalmente alada, de livro aberto em rede em relação às ideias de livro impresso e de livro eletrônico fechado, e-books, tal qual são comercializados atualmente.

A diferença consiste no fato de se buscar 
um meio de transcrever, escrever, gravar e ordenar, sim, partes do gigante quase-livro-rede e das múltiplas bibliotecas cibernéticas, não com o intuito de cercear (e lucrar com) entradas e saídas, mas com a esperança de poder, em qualquer outro momento (tempo e lugar), pôr em fluxo valores específicos, vivenciados no presente, na imanência nossa de agora em forma de linguagem-acontecimento. Talvez a ideia de ave ou de livro aberto em rede já seja uma experiência de memória partilhada entre contemporâneos cientes de fiar, escrever e tecer sentidos ou entendimentos, tão particulares quanto simples, da complexidade cultural do nosso tempo e lugar. ${ }^{2}$ Enquanto tateamos no escuro, criamos, às claras, redes de semi-mini-livros espiralados, cuja estrutura fluida se inspira na dinâmica das aves em bando.

${ }^{2}$ Cf. http://escoladeredes.ning.com/ 


\section{Referências}

BENJAMIN, Walter. Sur le langage. In: Fuvres I. Paris: Éditions Gallimard, 2000.

BORGES, Jorge Luis. O livro de areia. São Paulo: Companhia das Letras, 2009.

CÍCERO, Antonio. Sobre Pearblossom Hwy. In: MAMMI, Lorenzo; SCHWARCZ, Lilia Moritz (Orgs.). $8 X$ fotografia: ensaios. São Paulo: Companhia das Letras, 2008.

HOHLFELDT, Antônio; MARTINO, Luiz; França, Vera (Orgs.). Teorias da Comunicação. Petrópolis: Vozes, 2001.

MAFFESOLI, Michel. No fundo das aparências. Rio de Janeiro: Vozes, 1996.

SANTAELLA, Lucia. A interatividade no ciberespaço. In: . Navegar no ciberespaço: o perfil cognitivo do leitor imersivo. São Paulo: Paulus, 2004.

Submetido para avaliação em 01 de dezembro de 2010.

Aprovado para publicação em 31 de julho de 2012.

\section{Ana Beatriz Barroso}

Professora adjunta do departamento de Artes Visuais - Instituto de Artes, Universidade de Brasília. Brasília - DF, Brasil. E-mail: abeatrizb@gmail.com 